\title{
WEBSTER'S OPERATION FOR ENTROPION OF THE UPPER LID
}

BY

\author{
Alex. MacRae, M.D., D.O.M.S. \\ NEWCASTLE-ON-TYNE
}

At least forty different methods have been devised of operating for the relief of entropion of the upper lid. My excuse for adding to this formidable list is the belief that the method I describe which, so far as I am aware, is almost unknown to ophthalmic surgeons in this country, is superior to them all.

If any enthusiast for another method is inclined to challenge this statement let me ask him this-has he never had bad results, either functional or cosmetic, from his entropion operations? My own experience of other operations for entropion of the upper lid has not been a happy one; and when I say that the operation I describe, and which I have performed many hundreds of times, has always in my hands been successful, and has never given any trace of deformity or a bad cosmetic result ; and that, if recurrence did take place, it could be repeated without difficulty, I think I have some grounds for claiming it to be the best yet devised.

I make no personal claim in the matter. The operation was not invented by me and though it is possible that experience may have slightly modified my technique from that which I was taught, the essential features of the operation are not original. I am writing in the hope that what I consider the best operation for this condition may find its way into the text-books and displace many of the old (some of them barbarous and mutilating) procedures which are still described.

MacCallan, whose twenty years' experience as Director of Ophthalmic Hospitals in what is probably the most trachomatous country in the world, gives him some right to speak with authority, tells in a recent paper ${ }^{(1)}$ how on arrival in Egypt he found the methods he had learnt at home inadequate, and was put in the humiliating position of having to learn better methods from his subordinates. In the course of these twenty years he came to adopt three alternative operations for entropion. They were :

(1) A modified van Millingen in which the lid margin is split by an incision in the grey line and a flap of mucous membrane from the lip inserted in the gap.

(2) The Snellen-Streatfeild operation-in which a wedge is taken from the tarsal plate through an incision on the skin surface of the lid.

(3) The combined excision operation-in which the whole plate is removed through the conjunctival surface of the lid. 
Now, however excellent these operations are in the hands of an expert, if badly performed each of them may lead to considerable deformity.

van Millingen's operation at best thickens the margin of the lid and if healing is irregular may give anything but a pretty result. It does not deal with the cause of the deformity-the distorted tarsal plate; and in common with all operations in which the lid is split in the grey line there is the risk of some of the hair bulbs remaining in the posterior half of the split lid.

The Snellen-Streatfeild operation I have known to cause most unsightly defects in the lids : while even so warm an advocate of "combined excision" as Maynard( ${ }^{(2)}$ acknowledges that the slightest irregularity in the final stitching may cause bad cosmetic effects not easily repaired.

The operation I describe is practically fool-proof. Even if the graft should 'fail to "take," owing to carelessness or want of skill in getting it into position, no harm is done: the lid is not distorted, neither skin surface nor lid margin has been touched by knife or suture and the patient is no worse off than before. $\mathrm{He}$ is indeed in the position of one who has had the original Burow's operation performed, and is at least temporarily benefited, and in no way disfigured.

Perhaps it may be thought that I lay too much stress upon cosmetic results. If your operation relieves a man of the misery caused by cilia rubbing on his cornea, he may be grateful, however ugly his lid may look. But even so, a notched and distorted lid (no uncommon result after many entropion operations) may be almost as great a menace to his sight as the trichiasis; if on closing the lid any gap is left, the cornea is not properly protected either during waking hours or when asleep; while a rough or irregular lid margin may cause as much injury to the sensitive cornea as the inturned lashes did.

Besides, a considerable proportion of one's patients in trachomatous countries are women, and as no defect is more apparent than a mis-shapen evelid, an operation which cures the trichiasis but leaves deformity, will lower your patient's value in the marriage market and may be the cause of life-long misery.

The method was taught me, some eighteen years ago, during a visit to Beyrout, by Dr. Webster, Ophthalmic Surgeon in the American College there. He had invented it twelve years before and had been so pleased with his results that he had abandoned all other procedures.

The method which I describe is that which I came to use: whether or not it conforms in every way with Dr. Webster's I cannot remember. It differs from most of the methods which 
employ a similar incision in that no stitch at all is applied to the eyelid.

From the day I learned it, until I left Arabia ten years later I used no other method, and in many hundred operations I do not know of any failure.

\section{Details of Operation}

The patient is prepared for a general anaesthetic. I have no doubt the operation could be done under local anaesthesia but a general anaesthetic makes it easier. The face and eyelids are cleaned with, say, 1/40 carbolic, paying particular attention to the lid margins; and the conjunctival sac is thoroughly washed out with hydrarg. perchlor. sol. 1 in 4,000 .

A Snellen's entropion clamp is used reversed: the left-sided clamp being used for the right eye and vice versa. The flat plate of the clamp is applied to the skin surface of the lid the open arm to the conjunctival surface, and the lid everted. The outer end of the lid is grasped with toothed forceps and pulled outwards until the punctum is just visible in the portion of the lid included in the clamp. The clamp is then screwed tight. An incision is now made in the conjunctival surface of the lid parallel to the lid margin and about $3 \mathrm{~mm}$. from it. This incision goes from end to end of the lid and goes right through the tarsal plate. It is not advisable to go so deep as to button-hole the skin surface but no. great harm is done if this accident happens. The important point is that the tarsal plate must be completely divided. At each extremity of the lid the incision is curved a little forwards towards the lid margin, but it must stop short of the actual margin, or the cosmetic result will not be so good. At the inner extretmity this forward curve should end just external to the punctum. It may not be possible, even if a large clamp is used, to complete the outer end of the incision without moving the lid in the clamp, but this is easily done by grasping the lid with toothed forceps, the clamp being slightly slackened meanwhile.

A stout Graefe knife is quite adequate for the incision but a. short and narrow bladed scalpel (e.g., a Lándolt's with middle points or a chalazion knife such as Messis. Weiss make) is easier to control.

On completion of the incision the wound is carefully inspected to see that no hair roots have been left in the proximal part of the lid. If the incision is made $3 \mathrm{~mm}$. from the border there should be none; but if at any point it has got too near some may be left and in any case it is wise to look for them. If any are seen they are carefully dissected out.

The clamp is now removed; the lid is replaced and a large moist pad pressed on it. Bleeding is at first free but has stopped by the 
time it is necessary to proceed with the final stage of the operation on the lid.

If both eyes are affected the other lid is incised in the same way and in its turn covered with a pad.

The inner surface of the lower lip is now cleansed by an assistant and held everted. The operator picks up a point of mucous membrane towards the angle of the mouth with toothed forceps held in his left hand, and with scissors, preferably curved on the flat, rapidly cuts a strip of mucous membrane of somewhat more than the length of his lid incision and $4 \mathrm{~mm}$. or $5 \mathrm{~mm}$. broad. The wound in the lip is immediately sutured by an assistant with a continuous suture. If no assistant is available it may be clamped and dealt with later.

The strip of mucous membrane is now laid on the palmar surface of a finger of the operator's left hand, raw surface exposed. From the raw surface the fat and submucous tissue are carefully removed, with, e.g., iris scissors curved on the flat, until the strip is so thin that it is difficult to tell which surface is which. This is the most troublesome and tedious part of the operation, as it is easy to button-hole the delicate graft and so render it useless, necessitating the cutting of another graft. It is important to perform it thoroughly, as the thinner the graft the better apposition can be got with it, and the more certain it is to "take." When sufficiently thin its sides are trimmed parallel and the ends pointed. The graft may now be transferred, till wanted, to a bowl of warm saline lotion or may be kept on the finger if the operator is not likely to forget it and let it be rubbed off during the next stage. Keeping it on the finger with the raw surface exposed saves one straining one's eyes later on to make out which is the raw surface.

The pad is now removed from the eye, blood wiped away and the lid everted. The line of the incision will be found filled with clot. The bulk of this is very gently removed by forceps or by swabs so as not, if possible, to restart the haemorrhage. The graft is then placed in position, convenient instruments for this purpose being a pair of fine-pointed, light, dissecting forceps and an iris repositor. If found to be too long it is shortened. Finally, it should lie in, and covering the groove made by the incision, the pointed ends lying in the two curved ends of the groove, care being taken that it is pressed well down on to the iid and that its edges are not curled in. It does not matter if the sides of the graft over-lap the sides of the groove, in fact it is probably better that they should; but the points must lie in the groove, as otherwise they are apt to get out of position on closing the eye. If any bleeding has restarted on removing the clot, it will cease as soon as the flap is in position. 
The lid, which has been everted, is now gently replaced. The lid margin is then cautiously raised with the finger and the conjunctival surface inspected to make sure that the graft has not been displaced in the act of replacing the lid. If it has, it is smoothed into position by the iris repositor without again everting the lid. A pad and bandage are then applied.

I used to dress the eyes daily, the first two or three dressings being done as gently and carefully as a first dressing after cataract extraction, to prevent any displacement of the graft. Possibly MacCallan's method of applying a thick layer of sterile boric ointment, and leaving for some days would do as well. It would save time. I describe what I have done.

If the operation and the subsequent dressing have been done as detailed above, the graft will invariably remain in position and "take." As the lid margin has not been interfered with and no stitches have been inserted there is no possibility of disfigurement. The bandage may be left off after the fifth day and a few days later it is quite safe to evert the lid to carry on any treatment thought advisable, if active trachoma is still present.

\section{Operations resembling Webster's}

Somewhat similar operations have been described at various times.

The principle of dividing the tarsal-plate parallel to the lid margin from the conjunctival surface we owe to Burow ${ }^{(3)}$, though his method of making the incision differs from that described. Burow's whole operation consists in the incision. This always gives temporary and sometimes permanent relief, but naturally when it heals there is often recurrence. No effort was made to keep the wound gaping nor to fill it in with a graft.

An incision similar to Webster's is made in the operations associated with the names of Williams ${ }^{(4)}$, Lagleyze ${ }^{(5)}$, Green ${ }^{(6)}$, and Ewing ${ }^{(7)}$. In none of these operations is a graft inserted; the wound is kept gaping by means of sutures applied in various ways.

Two other operations bear more resemblance to Webster's, viz., those of Gifford and Maher. Gifford ${ }^{(8)}$ applied a graft without suturing as in Webster's operation, but he described his incision as going nearly through the tarsal plate; and the terminal portions, which are at $45^{\circ}$ to the main incision, end between the cilia. This, I think is a mistake, as it notches the all important posterior border of the lid margin. Another possible cause of deformity is his method of making the wound gape (probably necessary because his incision does not go completely through the tarsal plate) by placing a pad along the skin surface contiguous to the lashes and tying sutures over it from above and below. 
Maher $^{(9)}$ in $189 \pi$ described an operation very similar in its essentials to Webster's-the main differences being : (1) that his incision is made with scissors, more or less in Burow's manner; and (2) that his graft is fixed by means of sutures at each enda loop on the graft, the knot on the skin surface. These sutures I consider quite unnecessary, and possibly harmful.

Maher published another paper ${ }^{(10)}$ on this operation in 1914, because he found that after the lapse of seventeen years it had still not won general recognition, and because he was convinced after hundreds of operations that it gave better results than any other operation.

I hope that Webster's operation, which I believe for reasons given to be better still, may win the recognition it deserves. I would most strongly urge young surgeons who may be going to trachomatous countries to begin their operative treatment of entropion by an operation which will never fail.

Note.-Since this article was written I have had the pleasure of submitting it to Dr. Webster who states that the method and technique I have described are almost identical with his own. He tells me. he frequently does the operation under local anaesthesia ( 1 per cent. novocaine) though on the whole he prefers a general anaesthetic. He now leaves the eye unbandaged after the first twenty-four hours, merely keeping it protected by a flap of lint kept moistened with boric lotion. He has performed the operation more than 5,000 times and for many years past has not had a case in which the graft has failed to take. Occasionally he has found it necessary where his first graft has been too short or too narrow to insert a supplementary graft at a later date. These small grafts he always inserts under local anaesthesia.

\section{REFERENCES}

1. MacCallan. -Trans. Ophthal. Soc. U.K., Vol. XLV, p. 1, 1925.

2. Maynard.-" Manual of Ophthal. Operations," 2nd edition, p. 175, 1920.

3. Burow.-Original article not traced. Vide de Schweinitz "Diseases of the Eye," 10th edition, p. 700, 1924.

4. Williams.-Liverpool Med.-Chir. Jl., p. 319, 1882. Vide Grimsdale and Brewerton "Ophthalmic Operations," 2nd edition, p. 112, 1920.

5. Lagleyze.-Arch. de Oftal. Hisp.-Amer., Vol. V, p. 1, 1905. Vide Grimsdale and Brewerton, p. 114.

6. Green.-Trans. Amer. Ophthal. Soc., Vol. III, p. 167, 1880. Vide Grimsdale and Brewerton, p. 114.

7. Ewing.-Trans. Amer. Ophthal. Soc., Vol. IX, p. 15, 1900. Vide Grimsdale and Brewerton, p. 115.

8. Gifford.-Amer. Jl. of Ophthal., Vol. IX, p. 1, 1892. Ophthalmoscope, Vol. XII, p. 698, 1914.

9. Maher.-Arch. of Ophthal., Vol. XXVI, p. 340, 1897.

10. Ibid. -Ophthalmoscope, Vol. XII, p. 206, 1914. 